\title{
Marrow biopsy in the diagnosis of pyrexia of undetermined origin ${ }^{1}$
}

\author{
N. D. GOWER \\ From the Department of Pathology, Edgware General Hospital, Middlesex
}

SYNOPSIS Marrow from 62 cases of pyrexia of undetermined origin was examined cytologically, histologically, and bacteriologically. Diagnostic findings were present in five cases ( $8 \%$ ), but all these patients presented definite clinical or haematological indications for marrow biopsy. It is concluded that marrow examination is useful in the diagnosis of pyrexia of undetermined origin but that cases for study must be selected in the light of general principles. Fever alone, even though prolonged and undiagnosed, is not an indication for marrow biopsy.

The clinical pathologist is frequently asked to examine the bone marrow in cases of perplexing fever when other diagnostic resources have been exhausted, but no systematic study of the value of marrow biopsy in the diagnosis of cases of pyrexia of undetermined origin has hitherto been undertaken.

The value of marrow biopsy in the diagnosis of non-haemopoietic diseases has been widely explored. Early work in this field is summarized by Leitner (1949), and subsequently marrow examination has been found useful in the diagnosis of metastatic carcinoma (Weisberger and Heinle, 1949; Berkheiser, 1955; Pillers, Marks, and Mitchell, 1956) and lymphomata (Cooper and Watkins, 1949; Pettet, Pease, and Cooper, 1955; Agress, 1957; Varadi, $1955,1960)$. Pease $(1952,1956)$ has made a special study of granulomatous lesions in marrow and she has shown that whilst granulomata can be found in a great variety of diseases a specific diagnosis may be made in tuberculosis, brucellosis, and histoplasmosis by demonstration of the causative organism.

Bacteriological examination of the marrow was not regarded highly by Leitner, but many successful isolations of tubercle bacilli from marrow are on record (Schleicher, 1946; Katz and Lifschutz, 1950; Choremis and Pantazis, 1952). Mallén, Hube, and Brenes (1947) found marrow culture useful for the isolation of the causative organism in cases of bacterial endocarditis and the monumental studies

'This paper has been abstracted from part of a thesis accepted in the University of London for the degree of M.D.

Received for publication 6 September 1962. of Saito (1955) indicate its value in typhoid and paratyphoid fevers.

In parasitology marrow examination is now largely restricted to the demonstration of the parasites of leishmaniasis and it has similarly lost favour as a means of demonstrating the L.E. cell phenomenon, although Louis and Limarzi (1958) have recently shown that the number of positive tests may be increased by examining blood and marrow in parallel.

Some of the diseases mentioned in this very brief outline of the application of marrow examination to general diagnosis figure prominently in lists of causes of pyrexia of undetermined origin, but a search of the literature reveals only 51 such cases in which the results of marrow biopsy have been reported. Diagnoses were made by marrow studies in 13 cases and these are presented in Table 1 . Apart from miliary tuberculosis and salmonella infections the diagnoses are confined to primary or secondary malignant disease of the marrow itself. The remarkably high proportion of successful diagnoses ( $26 \%$ ) is not, of course, of any statistical importance as the number of unreported negative findings is unknown, but must certainly be large.

\section{THE PRESENT INVESTIGATION}

CLINICAL MATERIAL This investigation formed part of a prospective study of the problems of pyrexia of undetermined origin. The original series consisted of 67 cases (Gower, 1961). Eight further patients have been added subsequently, making a total of 75. Patients were defined as having pyrexia of undetermined origin and were admitted to the series provided that they remained 
TABLE I

CASES OF PYREXIA OF UNDETERMINED ORIGIN DESCRIBED IN THE LITERATURE WITH MARROW STUDIES PROVED DIAGNOSTIC

\begin{tabular}{lll} 
Author & Diagnosis & Bone Marrow Findings \\
\hline Catlin. Bintcliffe, and Marson (1947) & Renal carcinoma & Metastases present (bone biopsy) \\
Jaimet and Amy (1956) & Prostatic carcinoma & Metastases present \\
Pappworth (1948) & Hodgkin's disease & Diagnostic \\
Schilling (1957) & Myelomatosis & Diagnostic \\
Maizels (1956) & Myeloid reticulosis & Diagnostic \\
Magyar (1957) & Paramyeloblastic leukaemia & Diagnostic \\
Hand (1958) & Monocytic leukaemia & Diagnostic \\
Oppel and Berntsen (1954) & Pernicious anaemia & Diagnostic \\
Horowitz and Gorelick (1951) & Miliary tuberculosis & M. tuberculosis isolated \\
Polachek and Lerner (1955) & Miliary tuberculosis & Tuberculous granulomata present \\
Agress (1957) & Miliary tuberculosis & Tuberculous granulomata present \\
Flanders and Scott (1955) & Typhoid fever & Salmonella typhi isolated \\
Petersdorf and Beeson (1961) & Salmonellosis & Salmonella montevideo isolated
\end{tabular}

ill, febrile, and undiagnosed after two weeks' observation and investigation in hospital, and that they exhibited no leading symptoms or localizing physical signs. An oral temperature exceeding $100^{\circ} \mathrm{F}$. was accepted as evidence of fever. Repeated haemoglobin estimations, leucocyte counts, blood film examinations, sedimentation rates estimated by Westergren's method, blood cultures, urine examinations and cultures, and chest radiographs had been performed on all patients during the initial period of study. In most cases Widal and brucella agglutination titres, Paul Bunnell tests, Wassermann reactions, and examinations for L.E. cells were performed at least once during this period, and more specialized investigations, including virus antibody studies and liver or muscle biopsies, were carried out on selected patients. These investigations did not provide information of diagnostic importance although non-specific abnormalities were commonly detected.

Arrangements were made to perform aspiration marrow biopsy on all patients as soon as they had been admitted to the series but for a variety of reasons only 62 of the 75 cases could be studied.

MATERIALS AND METHODS Marrow was usually aspirated from the mid-sternum, but significantly tender areas were selectively punctured.

A general cytological examination was carried out on smears and squash preparations stained by Leishman's method. Satisfactory preparations were obtained in all cases. Differential counts were performed on 1,000 cells, chiefly for the purpose of assessing the degree of plasmacytosis.

Material suitable for histological assessment was obtained in 55 cases. Sections were prepared by the method of Agress (1957) and stained with haematoxylin and eosin, and by Perls's method for iron. In the light of Pease's (1956) experience of the distribution of granulomata in marrow, sections were cut from at least two parts of each block.

In 54 cases part of the marrow was inoculated into glucose broth, with added penicillinase if the patient was receiving penicillin, and incubated aerobically. Subcultures were made onto blood agar at 48 hours, seven days, and 28 days, and incubated aerobically and anaerobically. Whenever sufficient material was available primary anaerobic cultures were also set up, but this was possible only in a few cases. Only two primary cultures had to be discarded because of contamination.

The rest of the marrow was allowed to clot and was $\cong$ incubated at $37^{\circ} \mathrm{C}$. for two hours. Leishman-stained films were made and examined for the L.E. cell phenomenon. 3

Routine examination and cultures for tubercle bacilli $\stackrel{2}{<}$ were not included in this study. It was felt that had $\vec{\oplus}$ granulomata been seen in any of the marrow sections then it would have been justifiable to repeat sternal puncture specifically for bacteriological examination, but the event did not arise.

RESULTS The diagnoses ultimately established in all 75 cases are given in outline in Table II. Marrow biopsy was diagnostic in five $(8 \%)$ of the 62 patients examined. Non-specific abnormalities were present in the marrows of a further 23 patients and in one of these cases misinterpretation of the findings resulted in misdiagnosis.

Granulomata were not found in any of the marrows

\section{TABLE II}

DIAGNOSES AND RESULTS OF MARROW STUDIES IN 75 CASES OF PYREXIA OF UNDETERMINED ORIGIN

$\begin{array}{lll}\text { No. of } & \text { No. of } & \text { No. of } \\ \text { Cases } & \text { Marrows } & \text { Marrows } \\ & \text { Examined } & \text { Diagnostic }\end{array}$

Pyogenic infections

Tuberculosis

Protozoal infections

Virus infections

Collagenoses

Other inflammatory diseases

Carcinomata

Sarcomata

Lymphomata

Leukaemia

Miscellaneous disorders

Undiagnosed cases

Totals 
sectioned, nor was the L.E. cell phenomenon positive in any case.

\section{DIAGNOSTIC FINDINGS}

The diagnosis was established in four cases by cytological examination of the marrow. There was one case of aleukaemic leukaemia, two cases of malignant reticulosis apparently arising primarily in the marrow, and one case of metastatic carcinoma. In a fifth patient marrow cultures enabled a diagnosis of septicaemia due to Staphylococcus aureus to be made.

CASE 20 A boy, aged 5 years, developed migratory joint pains and fever. The sedimentation rate and antistreptolysin 0 titre were normal, and the symptoms did not respond to salicylates. The patient then developed measles after which he became quite well for several weeks when fever without joint pains recurred. The only relevant findings on investigation were moderate normochromic anaemia (Hb 9.0 g.\%), which improved spontaneously, and leucopenia (3,000 to 4,000 W.B.C.s per c.mm.) which persisted. The peripheral blood films showed no abnormality. Continuing unexplained leucopenia clearly called for examination of the marrow, which established the diagnosis of acute stem-cell leukaemia. Typical features of the disease did not develop for over three months.

CASE 21 A 24-year-old West African had suffered bouts of fever for nine months. Malaria was suspected but never proven, and anti-malarial therapy did not prevent the febrile attacks. Eventually fever became persistent and the patient lost weight. Investigation showed mild anaemia (Hb 10.5 g. \%) and leucopenia (3,700 W.B.C.s per c.mm.). The sternum was tender to pressure and examination of the marrow showed the presence of many abnormal reticulum cells. A few bizarre giant cells showing active erythrophagocytosis were also present. A diagnosis of 'myeloid' reticulosis was made. This was confirmed at necropsy, the marrow and liver being the organs principally involved.

CASE 74 A 60-year-old man was admitted to hospital with cellulitis of the left leg. This rapidly resolved, apparently in response to penicillin therapy, but fever persisted. Investigation showed no abnormality apart from moderate normochromic anaemia ( $\mathrm{Hb} 9.0 \mathrm{~g} . \%$ ), a neutrophil leucocytosis $(18,400$ W.B.C.s per c.mm., neutrophils $86 \%$ ) and an E.S.R. raised to $124 \mathrm{~mm}$. The possibility of myelomatosis was considered but this diagnosis was not supported by examination of the plasma proteins. Sternal puncture showed that the marrow was infiltrated by large lymphoid cells and a diagnosis of diffuse lymphosarcoma was made. Eventually splenomegaly became apparent, but at no time were abnormal cells found in the peripheral blood. The diagnosis was confirmed at necropsy, the spleen, marrow, and abdominal lymph nodes being the chief sites of lymphosarcomatous infiltration.
CASE 29 A woman, aged 66 years, complained of severe pain in the long bones, but as she had Paget's disease extensive investigation was not undertaken until she developed persistent fever. Only a normochromic anaemia (Hb 9.5 g. \%) and an E.S.R. of $98 \mathrm{~mm}$. were found. The peripheral blood films were normal. Radiographs of the bones showed changes typical of Paget's disease but sternal puncture disclosed disordered erythropoiesis and micrometastases of an anaplastic carcinoma. A small primary carcinoma of bronchus was discovered at necropsy.

CASE 3 A diabetic woman of 59 years had fever and severe pain in the right thigh. The pain soon subsided, but fever continued and became swinging in character. A diagnosis of septicaemia was made, but repeated blood cultures were sterile. The fever failed to respond to penicillin or later to chloramphenicol. Cultures of the marrow yielded a heavy, pure growth of Staphylococcus aureus sensitive to erythromycin. Her condition improved while she was receiving erythromycin but after six weeks she was found to have osteomyelitis when the right femur fractured spontaneously. Ultimately antibiotic therapy was successful but surgical intervention was necessary to obtain bony union of the fracture.

\section{NON-SPECIFIC FINDINGS}

These fell into three groups: marrows showing disordered haemopoiesis, those showing defective haemoglobin synthesis in the presence of adequate iron stores, and those showing a plasmacytosis.

In only one patient was disordered haemopoiesis seen without a specific diagnosis being made. This man had a relapsing fever and a pancytopaenia. The marrow was characterized by a high proportion of degenerating cells. The erythroblasts showed coarse cytoplasmic stippling with frequent abnormal mitoses and persistence of multiple nuclei. Stromal cells, reticulum cells, and lymphocytes were numerous. Good sections could not be obtained but at necropsy the diagnosis proved to be Hodgkin's disease with extensive marrow involvement.

A number of the anaemic patients studied had adequate or excessive deposits of stainable iron in the marrow, but usually the anaemia was normochromic. Five patients, however, showed rather severe hypochromic anaemia, with haemoglobin levels of 7 to $8 \mathrm{~g} . \%$ and a mean corpuscular haemoglobin concentration of $26 \%$ or less, in whom erythropoiesis was micronormoblastic yet the marrow contained considerable deposits of iron. All five patients had malignant disease, there being two cases of renal carcinoma and one case each of bronchial carcinoma, metastatic carcinoma of uterine origin, and retroperitoneal sarcoma.

Seventeen patients showed a marrow plamacytosis of more than $5 \%$. Eight of these patients remained 
undiagnosed, usually recovering, and five had a collagen disease. There was one case each of Hodgkin's disease, carcinoma of colon, ulcerative colitis, and disseminated sclerosis with urinary infection.

\section{MISDIAGNOSIS}

A misdiagnosis of histiocytic reticulosis was made in a patient with cholangitis whose marrow contained many large monocytoid cells engaged in erythrophagocytosis. Fortunately the physician was not impressed with this diagnosis, which the patient's subsequent history has shown to be wrong.

\section{FAILURES}

Apart from the previously mentioned case of disseminated Hodgkin's disease, there were four patients with conditions in which marrow biopsy could possibly have been diagnostic, but in whom it gave no useful information. They sere suffering from sarcoidosis, septicaemia caused by Staphylococcus albus, systemic lupus erythematosus, and retroperitoneal sarcoma with bone metastases.

\section{DISCUSSION}

Of the 75 patients studied, 24 were suffering from diseases which may sometimes be diagnosed by examination of the marrow. However in only 13 cases $(17 \%)$ was there later clinical evidence to suggest dissemination of the disease to such an extent that diagnosis by marrow studies, whether cytological, histological, or bacteriological, could be regarded as a reasonable possibility. Apart from the five patients diagnosed and the five cases in which marrow biopsy failed to give useful information, there were three patients with miliary tuberculosis, malaria, and septicaemia caused by Staphylococcus albus respectively, in whom marrow biopsy was not performed but in whom there was at least the possibility that it might have been diagnostic. Furthermore a diagnosis could probably have been made in the case of disseminated Hodgkin's disease had marrow studies been more vigorously pursued. Abnormal marrow was aspirated on three occasions and it is clear that we should have proceeded to trephine biopsy. Even had all these speculative successes been achieved diagnosis by marrow biopsy would only have been made in nine of the 75 cases $(12 \%)$ and it is probable that this figure gives a measure of the best results to be expected of it in the diagnosis of cases of pyrexia of undetermined origin as defined here.
As no similar series of cases has been recorded there are no figures with which to compare these results. The findings, however, are in agreement with the few published cases presented in Table $I$, in that, apart from an occasional case of septicaemia, the only diagnoses likely to be made by marrow studies in cases of pyrexia of undetermined origin are of diseases of the marrow itself. In these cases there is usually a definite haematological indication, such as unexplained anaemia, persistent leucopenia, or an unexpectedly high E.S.R., for examining the marrow. This has been the experience not only in the present series but in the few previously described cases, and is simply an application of the principle that blind biopsy of grossly normal tissue is seldom rewarding.

No definite valıe, even in indicating the group of diseases most likely to be causing symptoms, could be ascribed to the finding of non-specific marrow abnormalities. Marrow plasmacytosis has been observed in a great variety of diseases, but especially in rheumatoid arthritis and other collagen disorders (Hayhoe and Smith, 1951; Klein and Block, 1953) and has often been associated with an increase in plasma globulins. Following Fadem (1952) a rather high level $(5 \%)$ was set as the upper limit of normal for the frequency of plasma cells in marrow in this series. At this level half the cases of collagen diseases seen had a plasmacytosis, but so did an even higher proportion of patients who recovered without diagnosis, although only two patients with neoplasms showed a plasmacytosis of this degree. Nevertheless in the individual patient the finding of a marrow plasmacytosis could not be relied upon as evidence in favour of any particular type of disorder.

Severe hypochromic anaemia in the presence of adequate iron deposits in the marrow was only seen in patients with malignant disease. These patients did not show a true sideroblastic anaemia and conditions such as thalassaemia, refractory normoblastic anaemia, and pyridoxine-responsive anaemia were excluded in all cases. Removal of a hypernephroma in two patients was followed not only by cessation of fever but by repair of the anaemia.

It would not be justifiable to draw conclusions from this very small group of patients, especially as extensive studies on the mechanism of their anaemias have not been undertaken, but it seems reasonable to suggest that the association of unexplained fever and atypical hypochromic anaemia should be regarded as due to malignant disease until disproved. With this possible exception the finding of a normal marrow, or one showing non-specific changes only, in a case of pyrexia of undetermined origin is helpful only in excluding primary haemopoietic disease. 
I am indebted to the physicians of Edgware General Hospital, Central Middlesex Hospital, and King's College Hospital for their courtesy in allowing me to study their patients, and to Dr. J. L. Hamilton Paterson for his advice during the preparation of this paper.

\section{REFERENCES}

Agress, H. (1957). Amer. J. clin. Path., 27, 282.

Berkheiser, S. W. (1955). Cancer. (Philad.), 8, 958.

Catlin, C. H., Bintcliffe, E. W., and Marson, F. G. (1947). Lancet, 2, 170.

Choremis, C., and Pantazis, S. (1952). Ibid., 1, 748.

Cooper, T., and Watkins, C. H. (1949). Blood, 4, 534.

Fadem, R. S. (1952). Cancer (Philad.), 5, 128.

Flanders, J. F., and Scott, E. G. (1955). Delaware med. J., 27, 141.

Gower, N. D. (1961). Thesis, London.

Hand, W. J. (1958). Med. Clin. N. Amer., 42, 43.

Klein, H., and Block, M. (1953). Blood, 8, 1034.

Leitner, S. J. (1949). Bone Marrow Biopsy, translated by C. J. C. Britton and E. Neumark. Churchill, London.

Louis, J., and Limarzi, L. R. (1958). J. chron. Dis., 8, 596.

Magyar, I. (1957). Orv. Hetil., 98, 1001.

Maizels, M. (1956). Univ. Coll. Hosp. Mag. (Lond.), 40, 161.

Mallén, M. S., Hube, E. L., and Brenes, M. (1947). Amer. Heart. J., $33,692$.

Oppel, T. W., and Berntsen, C. A. Jr. (1954). Med. Clin. N. Amer., 38, 891.

Pappworth, M. H. (1948). Postgrad. med. J., 24, 81.

Pease, Gertrude L. (1952). Amer. J. clin. Path., 22, 107.

- (1956). Blood, 11, 720.

Petersdorf, R. G., and Beeson, P. B. (1961). Medicine (Baltimore), $40,1$.

Pettet, Jacqueline D., Pease, Gertrude L., and Cooper, T. (1955). Blood, 10, 820.

Pillers, E. M. K., Marks, J., and Mitchell, J. S. (1956). Brit. J. Cancer, $10,458$.

Polacheck, A. A., and Lerner, G. (1955). Maryland med. J., 4, 199.

Saito, A. (1955). Tohoku J. exp. Med., 62, 161.

Schilling, V. (1957). Medizinische, No. 36, 1307.

Schleicher, E. M. (1946). Amer. Rev. Tuberc., 53, 115.

Varadi, S. (1955). Brit. J. Haemat., 1, 184.

- (1960). Brit. med. J., 1, 1239.

Weisberger, A. S., and Heinle, R. W. (1949). Amer. J. med. Sci., 217 263.
Katz, S., and Lifschutz, S. (1950). Med. Clin. N. Amer., 34, 1817.
Jaimet, C. H., and Amy, H. E. (1956). Ann. intern. Med., 44, 617 